PRZEGLĄD RUSYCYSTYCZNY 2021, nr 2 (174)

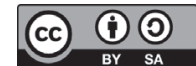

DOI 10.31261/pr.10086

\author{
НИКОЛАЙ ГАРБОВСКИЙ \\ Московский государственный университет, Москва, Россия \\ iD https://orcid.org/0000-0001-9267-3365 \\ ОЛЬГА КОСТИКОВА \\ Московский государственный университет, Москва, Россия \\ (iD https://orcid.org/0000-0003-3973-459X
}

\title{
«КРУТЫЕ ГАЛСЫ» РОССИЙСКОГО ПЕРЕВОДОВЕДЕНИЯ
}

\section{TRANSLATION STUDIES IN RUSSIA: DIFFICULT HALSES}

Russian translation studies emerged at the beginning of the 20th century. Its formation and evolution led to social transformations and the development of scientific thought in such areas as linguistics, philosophy, psychology, communication theory, etc. Various translation models and scientific paradigms replacing each other throughout the development of Russian translation studies reflect its interdisciplinary status. The plurality of approaches to understanding translation leads to the need to build a systemological model based on the synthesis of a set of data, perceived as something whole. This approach makes it possible to identify various types of links within such a complex object as a translation.

Keywords: Translation Studies in Russia, evolution of theoretical approaches, systemological paradigm

Мысль, подобно паруснику «ловит парусом ветер» то справа, то слева, и идет галсами чтобы продвигаться вперед, нередко лавируя во избежание губительного столкновения с опасными предметами.

От буквальной и грубой точности к изящной вольности; от преданности автору оригинала к его презрению в угоду читателю; от ориентирования на читателя перевода до его игнорирования; от полного разочарования в состоятельности перевода и провозглашения «непереводимости» до научного обоснования всеобщей «переводимости»; от возвеличивания смысла как основной ценности в переводе до его полного отрицания и возведения формы на вершину переводческого совершенства. Роджер Сейвори сформулировал хорошо известные нам парадоксы в представлениях о переводе и задачах переводчика, о рецептах, правилах, предписаниях переводчикам и кри- 
териях оценки перевода, известных из истории научной мысли о переводе. Так, то длинными, то короткими галсами наука о переводе шла вперед и формировалась в борьбе и единстве противоположностей.

Российская наука о переводе, зародившись на заре XX в., в условиях радикальных социальных преобразований, во многом обусловивших ход ее развития, впитала в себя идеи предшествовавшего периода. Как шло ее развитие в дальнейшем? Какие крутые «галсы», повороты - лингвистические, герменевтические, культурно-антропологические и пр. предопределили ее современное состояние?

Первые попытки построить советскую теорию перевода как теорию художественного перевода предпринимаются уже с первых лет советской власти. Менее чем через год после Октябрьской революции в атмосфере экономического и политического кризиса, в самый разгар гражданской войны правительство России стало проявлять заботу о культурном развитии и образовании людей.

В области культурной политики перед молодым советским государством стояла двойная задача.

Во-первых, новый режим стремился выполнить благородную миссию просвещения народных масс, вышедших на первый план в самых разных сферах жизни в новых социальных условиях, побудить их к чтению, приобщить к шедеврам мировой литературы.

Во-вторых, политическая власть в стране стремились поддерживать имидж России как цивилизованного государства, которое, несмотря на смену политического режима, открыто всему миру, а советских людей - как читающий просвещенный народ.

Решению этой задачи, в частности, должны были способствовать новые издания литературных произведений великих мастеров мировой литературы при поддержке государства.

С этой целью по инициативе и при личном участии Максима Горького и был задуман амбициозный проект при Комиссариате образования - Всемирная литература, получивший у современников название «утопии XX века». Проект предполагал перевод, публикацию и распространение в Советской России богатой коллекции шедевров мировой литературы, общим числом более 1500 произведений. Для реализации проекта 4 сентября 1918 года в Санкт-Петербурге было создано издательство Всемирная литература. 
Первым препятствием на пути реализации проекта, с которым столкнулись его идеологи, оказалась настораживавшая нехватка квалифицированных переводческих кадров. Поэтому, как отмечал один из активных участников проекта, молодой писатель, литературный критик и переводчик Корней Иванович Чуковский, перед издателями встала задача

повысить уровень переводческого искусства и подготовить кадры молодых переводчиков, которые могли бы дать новому советскому читателю, впервые приобщающемуся к культурному наследию всех времен и народов, лучшие книги, какие только есть на земле ${ }^{1}$.

По истечении почти столетия с того момента и после очередного крутого галса в жизни российского общества можно увидеть в этом замысле и еще одну причину: стремление уничтожить во имя «обновления» все то, что было сделано предшественниками. Это хорошо согласовывалось с революционной риторикой времени - достаточно вспомнить слова международного пролетарского гимна Интернационала французского поэта Эжена Потье, ставшего (в переводе на русский язык Аркадия Коца) гимном молодой советской республики: «Весь мир насилья мы разрушим до основанья, а затем мы наш, мы новый мир построим....».

Но проект интересен еще и тем, что в нем впервые в российском литературном мире была заложена идея построения теории перевода художественной литературы.

Попытка научить переводу художественной литературы «на строго научных основаниях» требовала построения теории, отвечавшей сложности задачи. Чуковский отмечал, что

тогда не существовало ни одной русской книги, посвященной теории перевода. Пытаясь написать такую книгу, я чувствовал себя одиночкой, бредущим по неведомой дороге. Теперь это древняя история, и кажется почти невероятным, что, кроме отдельных - порою проникновенных - высказываний, писатели предыдущей эпохи не оставили нам никакой общей методики художественного перевода ${ }^{2}$.

Проект, который, к сожалению, воплотился в жизнь лишь частично, ознаменовал чрезвычайно важный для советской науки о переводе поворот - первый «теоретический галс», а именно

1 К. И. Чуковский, Высокое искусство, Советский писатель, Москва 1968, с. 7.

2 Там же. 
переход от эмпирической стадии научного знания к теоретической и зарождение первой научной парадигмы, которую можно было бы определить как литературно-критическую по содержанию и как методологическую по ее прагматике.

Горький и его единомышленники, литераторы-переводчики, поэты и писатели Батюшков, Гумилев, Крачковский, Лозинский, Чуковский и другие, выступали ключевыми фигурами на этом этапе, который характеризовался попытками преодоления теоретического хаоса, свойственного предшествовавшей, эмпирической, стадии, и построения неких первых теоретических представлений о переводе.

Для этого впервые в истории переводческой практики в России издательством был создан семинар по литературному переводу. Сам факт создания этой мастерской важен для понимания истории перевода в России. Для участников семинара в 1919 году скромным тиражом для внутреннего пользования издается небольшая брошюра, некое «руководство» молодым переводчикам - Принципы художественного перевода. Брошюра содержала две статьи: Перевод в прозе Чуковского и Переводы стихотворные Николая Гумилева, что отражало представления о двух аспектах литературного перевода. Бельгийский исследователь истории и теории перевода Анри Ван Оф назвал эту брошюру «эмбрионом теоретических трудов по переводу в России» ${ }^{3}$.

Кристиан Балью разделяет мнение коллеги: «возможно - пишет он - речь идет о первом русском тексте по теории перевода и о первых курсах в этой области после Октябрьской революции, о которых в истории сохранилось лишь имя Чуковского»4.

В самом деле, даже более чем через 6о лет Андрей Федоров, в своих Основах общей теории перевода, вышедших в 1983 г., упоминая эту брошюру, отмечает лишь вклад Чуковского в отечественную науку о переводе 5 .

Таким образом, теория перевода рождается из необходимости научить переводу, что раскрывает ее прагматичный характер.

Но нельзя полагать, что выбор теоретического «галса» вместо

3 H. Van Hoof, La traduction au pays des Tsars et des Soviets, «Meta» 1990, vol. 35, № 2, с. 288. (перевод наш - Н.Г, О.К.).

4 C. Balliu, Clefs pour une histoire de la traductologie soviétique, «Meta» 2005, vol. 50, № 3, с. 936. (перевод наш - Н.Г, О.К.).

5 А. В. Федоров, Основы общей теории перевода (лингвистические проблемы), Высшая школа, Москва 1983. 
предшествовавшего предопределил ровный и стройный курс развития науки о переводе в России.

С самого начала и по сей день внутри этого широкого, бурно развивающегося потока теоретической и литературно-критической мысли очевидно лавирование между двумя ориентирами: на читателя перевода или на автора оригинала. И если первое направление развивалось в русле социалистического реализма, то второе шло по пути формализма. Это лавирование как нельзя лучше отражало философский тезис о единстве и борьбе противоположностей.

Противоречие, пока еще не антагонистическое, можно увидеть уже в концепциях авторов упомянутой брошюры: Чуковский ориентировался на читателя, для Гумилева важна была поэтическая форма, точнее, строгое следование формальным признакам оригинального произведения.

По его мнению, для переводчика, достойного имени поэта, только форма имеет значение. Форма - это единственное средство выразить дух оригинала 6 .

Несколько лет спустя, в 1923 году, немецкий философ и переводчик Вальтер Беньямин практически повторил тезис Гумилева, заявив, что перевод есть форма7.

Следование иным галсом в переводческом творчестве и в его теоретическом обосновании постепенно переросло в жестокое противоборство двух концепций: соцреализма и формализма.

Показательным является противостояние «формалистов» Евгения Ланна, Георгия Шенгели и др. представителей «технологически-точного перевода» сторонникам так называемого «творческого перевода» - школы соцреализма в художественном переводе Ивана Кашкина.

Ланн хорошо известен как переводчик прозы. Совместно с женой Александрой Кривцовой он перевел Посмертные записки Пиквикского клуба. Эта работа, переиздаваемая по сей день, как и его творчество в целом, вызвала бурную критическую реакцию как самого Кашкина, так и представителей кашкинской школы, в частности, Норы Галь.

6 Н. Гумилев, Переводы стихотворные// К. Чуковский, Н. Гумилев, Принцииы художественного перевода, Всемирная литература, Петербург 1919, с. 25-30.

7 В. Беньямин, Задача переводчика. Предисловие к переводу Парижских картин Бодлера (перев. Е. Павлова), «Комментарии» 1997, № 11, http:// www.commentmag.ru/archive/11/ 6.htm (15.10.2020). 
В статье, посвященной собственному методу перевода, Ланн отмечал, что «каждый переводчик великолепно знает, что значит «точный» перевод и что значит «неточный». По его мнению, принцип «художественно точного перевода» исключает соавторство переводчика. Недопустимы всяческого рода дополнения и какие бы то ни было пропуски. Если в тексте мы встречаем неясности, никаких истолкований переводчик «не должен себе позволить». Даже некоторые языковые особенности языка оригинала Ланн пытался сохранить в тексте перевода, придавая им определенное значение, например, повторы глагола речи в диалогах:

You are mad, - said Mr. Snodgrass

Or drunk, - said Mr. Winkle

Or both, - said Mr. Tupman ${ }^{8}$.

Нора Галь охарактеризовала переводы Ланна как сухие, формалистические, неудобочитаемые 9 . Кашкин вообще отказывал Ланну в таланте переводчика ${ }^{10}$.

Георгий Шенгели - теоретик поэзии, известен своими работами по теории стиха, что сближает его с Гумилевым. В его теоретических работах Трактате о русском стихе $(1918,1923)$, Техники стиха (1940) отчетливо видна его методологическая концепция соотнесения встречаемости разных стиховых форм с нормами языка.

Кашкин, выступая с резкой критикой каких бы то ни было формально точных методов в художественном переводе, отстаивал принципы «творческого подхода» к переводу литературных текстов. В построении теории перевода в советское время он усматривал блуждания и крайности, некую схоластическую игру, имевшие идеалистическую основу.

Напротив, метод социалистического реализма способен был, по его мнению, дать в переводе наилучшие результаты: в реалистическом методе, в его правдивости, в его исторической кон-

8 Е. Ланн, Стиль раннего Диккенса и перевод «Посмертных записок Пиквикского клуба, «Литературный критик» 1939, № 1, с 156-171.

9 Н. Галь, Воспоминания. Статьи. Стихи. Письма. Библиография, Д. Кузьмин (сост.), Арго-Риск, Москва 1997, http://www.vavilon.ru/noragal/memoir.html (115.10.2020).

${ }^{10}$ И. Кашкин, Ложный принции и неприемлемые результаты, «Иностранные языки в школе» 1952, № 2, с. 22-41. 
кретности Кашкин видел наилучшую гарантию верной передачи подлинника со всеми присущими ему качествами.

Подвергался критике среди прочих и количественный метод, а также принцип функционального подобия, предлагавшийся Шенгели в послесловии к его переводу Дон-Жуана.

Кашкин оспаривал и известное сравнение переводчика с прозрачным стеклом, приведенное Гоголем в отношении переводов Жуковского. По его мнению, стекло перевода легко теряет свою прозрачность, на нем становятся заметны царапины и пр. Разумеется, не могло остаться в стороне и зарождавшееся в 40-е годы стилистическое направление, разрабатывавшееся Федоровым, которое впоследствии переросло в доминировавшую полвека лингвистическую парадигму.

Заявив о себе в начале второй половины XX века учебным пособием Андрея Федорова (1906-1997), как о науке лингвистической, теория перевода поспешила прежде всего отмежеваться от литературно-критического подхода к переводу и «соответствовать» новейшим тенденциям лингвистической теории того периода.

Используя принятый образ, можно констатировать, что наука о переводе пошла иным галсом.

Федоров так определял свои задачи:

Для исследования переводов в их соотношении с оригиналами различение конкретного элемента языковой формы, с одной стороны, и его смысловой и художественной функции, с другой, обещало быть плодотворным тем более, что с этим совмещалась возможность и такого положения, когда формально различные элементы оказываются носителями одинаковой функции. Мысль об этом автор настоящей книги попытался развить в одной из своих ранних статей (Проблема стихотворного перевода 1927 г.), где, полемизируя с нормативным представлением об «идеальной точности», он предлагал рассматривать его в исторической обусловленности и где впервые было применено понятие «теория переводов ${ }^{11}$.

О книге Федорова $O$ художественном переводе, вышедшей в 1941 г. ${ }^{12}$, Яков Рецкер писал:

В его книге показано, что успешное сочетание теории и практики перевода возможно лишь на широкой филологической основе. Работа эта уже наме-

${ }^{11}$ А. В. Федоров, Основы общей теории перевода, Высшая школа, Москва 1983, c. 95.

${ }^{12}$ А. В. Федоров, О художественном переводе, ОГИЗ, Ленинград 1941. 
чала общие принципы лингвистического подхода к переводу текста, получившие дальнейшее развитие и уточнение во Введении в теорию перевода (1953 г.) и во 2-м (1958 г.) и в 3-м переработанном и дополненном издании под названием Основы общей теории перевода (Лингвистический очерк) 1968 г. $^{13}$

Федоров определил триединую задачу науки о переводе: задача этой научной дисциплины в том, чтобы

обобщать выводы из наблюдений над отдельными частными случаями перевода и служить теоретической основой для переводческой практики, которая могла бы руководствоваться ею в поисках нужных средств выражения и выбора их и могла бы черпать в ней доводы и доказательства в пользу определённого решения конкретных вопросов ${ }^{14}$.

В 60-е годы XX века под влиянием идей структурной лингвистики, а также в связи с проникновением в лингвистику идей кибернетики, в научный обиход входит понятие лингвистической модели. Исследователи перевода, тотчас откликнувшись на нововведение, приступили к созданию самых разнообразных моделей перевода. И если в лингвистике термин «модель» начинает приобретать то же содержание, что и термин «теория», то в науке о переводе термины «модель перевода» и «теория перевода» становятся синонимами.

Каждая из этих моделей представляла собой как бы отдельную теорию перевода, опиравшуюся на положения и использовавшую методы тех или иных направлений лингвистической науки. Так, трансформационная порождающая грамматика легла в основу трансформационной модели перевода; семантические теории (метод компонентного анализа, порождающая семантика и др.) породили семантические модели; коммуникативная лингвистика - коммуникативную модель перевода и т.п.

Такое положение было вполне понятным и оправданным, если учесть, что молодая теория перевода, с самого начала объявившая себя прикладной отраслью науки о языке, не могла не опираться на данные фундаментальной лингвистики. Однако это нередко приводило к тому, что авторы каждой последующей модели, если и не отрицали полностью предыдущие, то непре-

${ }_{13}$ Я.И. Рецкер, Теория перевода и переводческая практика. Очерки лингвистической теории перевода, Р. Валент, Москва 2007, с. 6.

${ }^{14}$ А.В. Федоров, Введение в теорию перевода, Издательство литературы на иностранных языках, Москва 1953. 
менно отмечали их односторонность и неспособность представить теоретическую картину перевода в целом. Само понимание тех или иных моделей перевода было далеко неоднозначным. Так, «ситуативная модель» трактовалась Виленом Комиссаровым как аналог «денотативной модели» ${ }^{15}$, а Александром Швейцером - как самостоятельная модель, наполненная совершенно иным содержанием.

И, тем не менее, на протяжении более четверти века модели перевода занимали видное место в работах по теории перевода. Появлялись новые направления и теории в лингвистике, тотчас начинали строиться новые модели перевода. При этом старое знание об исследуемом объекте, как правило, учитывалось недостаточно. Разумеется, каждая новая модель освещала какую-либо иную сторону перевода, дополняя общую картину научного представления объекта. Развитие теории перевода шло, таким образом, по пути не качественного углубления научных знаний, а лишь прибавления каждого нового знания к уже известному. Если сравнить этот процесс с процессом логического развертывания мысли, то можно сказать, что в теории перевода накопление научных знаний шло главным образом не путем сложной импликации, когда одни теоретические положения выводятся из других, а путем конъюнкции, т.е. добавления одного знания к другому.

В итоге, признавалось, что каждая модель перевода дает верное теоретическое представление о каком-либо одном аспекте перевода, но взятые вместе они способны составить достаточно стройную научную картину перевода как особой разновидности двуязычной коммуникативной деятельности.

В то же время перевод все чаще становился объектом исследования разных научных дисциплин. Лингвистическое направление стало уступать место междисциплинарным исследованиям.

Произошел очередной выбор нового галса.

Если говорить о переводе как об объекте, то в этой области научных разысканий оказываются такие аспекты, как «лингвистика перевода», «философия перевода», «социология перевода», «психология перевода», «сравнительное литературоведение», «семиотика» и др., которые, строго говоря, являются предметами соответствующих научных дисциплин.

${ }^{15}$ В. Н. Комиссаров, Современное переводоведение, ЭТС, Москва 2001. 
К переводу обратились философы неогерменевтического направления Поль Рикер, Мишель Фуко, Жак Деррида и др. Структурные антропологи и семиологи не отставали от коллег-философов.

Ролан Барт сделал массу интересных наблюдений, полезных для теории перевода, способных развить ее особенно в семиотических аспектах. Сакраментальный вопрос о том, что первично в переводе - смысл или форма, порождает множество производных вопросов: Что такое смысл? Как коррелируют смысл и значение? Свободна ли форма от смысла? В чем смысл переводческого воспроизведения формы? Воспроизводима ли форма в переводе? Как образ - основа художественного творчества, способен найти эквивалент в переводе? И многие другие.

Обратимся к проблеме образности в переводе. Для перевода первична именно образная эквивалентность. Эквивалентность же языковая - вторична. Она подчинена первой, но, подчас, способна увести нас далеко от первой.

Иначе говоря, перевод представляется, прежде всего, как сложная игра образов, где воображаемое автора исходного текста коррелирует с воображаемым переводчика, которое облекается в соответствующие дискурсивные формы. Но форма дискурса - это вещь в себе, которая способна осуществить метаморфозы смысла и вновь отправить нас к извечному вопросу о первичности смысла, а именно, задуматься над тем, до какой степени смысл первичен.

Выявление сущностных сторон перевода предполагает обращение именно к этим двум взаимосвязанным его аспектам, а именно, переводу, как образному отражению некой виртуальной реальности, заключенной в тексте оригинала, и как мастерству построения дискурса для облачения в приемлемую форму рожденных в сознании переводчика образов.

Именно такой взгляд на перевод сближает его с искусством.

Центральной категорией искусства является понятие художественного образа. Художественному переводу не чужды все категории литературного творчества, в том числе и данная категория.

В философии понятие художественного образа определяется как всеобщая категория художественного творчества, средство и форма освоения жизни искусством. Если она всеобщая, то должна распространяться и на переводческую деятельность, 
в противном случае, перевод не может быть определен как искусство в узком смысле слова, и выражение «Перевод - искусство» окажется лишь пустой, лишенной содержания фразой, уводящей нас в сторону от истинной сущности рассматриваемого нами объекта.

Центральной категорией перевода как деятельности является категория «эквивалентного образа». Действительно, какую бы проблему перевода мы не взяли, в конечном итоге она сводится к этой категории.

Понятие образа в философии и искусстве предполагает прежде всего его вторичность. Образ - это отражение, будь то результат познавательной деятельности человека или обобщенное художественное представление действительности. Образ повторяет в той или иной форме то, что существует помимо него и исторически предшествует ему.

Переводческий эквивалентный образ также является вторичным по отношению к тексту оригинала. По определению, эквивалентным является то, что равнозначно другому, полностью его заменяет. Заменять же можно только то, что существует помимо замещающего объекта и исторически до него. Следовательно, понятие образа соотносится с вторичными объектами, замещающими некоторые первичные.

Категория художественного образа включает в себя онтологический, семиотический, гносеологический и эстетический аспекты.

Онтологический аспект образа состоит в том, что он представляет собой факт идеального бытия, облеченного в вещественную основу, не совпадающую с вещественной основой воспроизводимого объекта реальной действительности. В самом деле, мрамор не есть живая плоть, а рассказ о событии не есть само событие.

Онтологический аспект представляется нам чрезвычайно важным для понимания сущности перевода и переводческого эквивалентного образа.

Перевод, равно как живопись, музыка, литература, в известной степени также представляет собой идеальное бытие, облеченное в вещественную основу, не совпадающую с вещественной основой воспроизводимого объекта: переводческие дискурсы вещественны, но они есть ни что иное как материальное обличие идеального бытия, каковым является психическая деятельность переводчика. 
Они также не совпадают по форме с воспроизводимыми объектами - знаками текста оригинала.

Иначе говоря, в онтологическом аспекте перевод не отличается от других видов искусства.

В семиотическом аспекте художественный образ есть знак, то есть средство смысловой коммуникации в рамках данной культуры. Близость перевода другим видам искусств в семиотическом аспекте очевидна.

Если художественный образ является знаком, то есть вещественным элементом, в котором зашифрована информация о каком-либо фрагменте действительности, то и избранный переводчиком эквивалентный образ также является знаком, в котором зашифрована информация о таком объекте действительности, каким, по представлению переводчика, является оригинал. Следует обратить внимание на одну из важнейших черт перевода, которая нередко упускается из вида и которая лежит в основе множества заблуждений как теоретического, так и практического планов: нередко полагают, что переводчик воссоздает реальность, описанную в оригинале. Но переводчик не воспроизводит вторично действительность, уже воспроизведенную однажды автором оригинала, он воспроизводит систему смыслов, образов, заключенную в оригинале, средствами иной семиотической системы, или, если признать одной семиотической системой человеческий язык в целом в противопоставлении другим знаковым системам, средствами иного семиотического варианта для иной культуры, для адресата, владеющего иным культурным кодом.

В гносеологическом аспекте художественный образ есть вымысел, то есть категория близкая той, что в теории познания называется допущением. Художественный образ является допущением, то есть гипотезой, в силу своей идеальности и воображаемости. Таким же допущением, характеризующимся идеальностью и воображаемостью, является и переводческий эквивалентный образ. Действительно, эквивалентность переведенного текста является идеальной и воображаемой. Идеальность и воображаемость переводческих эквивалентов демонстрируется с не меньшей очевидностью, чем при сравнении картин, написанных разными художниками с одной точки. В самом деле, в основе переводческой деятельности лежит индивидуальное восприятие текста оригинала и его субъективная способность вообразить, выбрать то, что представляется ему эк- 
вивалентным. Большинство переводческих эквивалентов - не более чем допущение.

Считается, что художественный образ является допущением особого рода, внушаемым автором художественного произведения с максимальной убедительностью. Так же можно охарактеризовать и переводческий эквивалентный образ.

Переводчик всегда стремится убедить читателя в том, что выбранный им эквивалент и есть максимально точное отражение того, что содержится в тексте оригинала.

Эстетический аспект художественного образа, равно как и эквивалентного переводческого образа, всецело зависят от выразительного мастерства автора и переводчика. Он отправляет нас уже ко второй составляющей сущности перевода, а именно, дискурсивной. Если эстетика художественного образа не допускает ничего случайного и механически служебного, то и переводческий эквивалентный образ в обличии форм языка перевода не может быть ни случайным, ни механически служебным. В оппозиции случайного и служебного отражается суть переводческих дискуссий двух тысячелетий, а именно, дискуссий о вольном и буквальном в переводе, то есть множества теоретических, методологических и аксиологических галсов.

Перевод является искусством перевыражения, но он отнюдь не является вторичным искусством, в том пейоративном значении, которое мы привыкли вкладывать в это определение. Переводчик не репродуцирует, подобно копиисту, уже существующее речевое произведение. Он действительно ограничен в известной степени рамками оригинального речевого произведения. Но искусство его не в том, чтобы повторить нечто, уже созданное. Его искусство в том, чтобы создать новое произведение в иной семиотической системе, для иной культурной среды, иногда и для иной эпохи. Перевод речевого произведения с одного языка на другой - это такой же творческий процесс, как постановка кинофильмов и спектаклей, создание опер и балетов по литературным произведениям, как живопись на библейские и другие литературные сюжеты и многие другие виды межсемиотического перевода.

Разумеется, феномен перевода может и должен изучаться с разных сторон, разными научными дисциплинами. Иначе говоря, многодисциплинарный подход к переводу как объекту изучения очевиден. Перевод - это когнитивная деятельность. Поэтому весь комплекс когнитивных наук привносит новые 
данные, предлагает методы, которые могут применяться и для изучения перевода.

Состояние же междисциплинарности, характерное для всякого научного направления, покидающего лоно какой-либо научной дисциплины в связи с тем, что ее границы стали слишком узкими, свидетельствует о зарождении новой научной парадигмы, основным методом которой оказывается уже не анализ, а синтез.

Именно синтез научных данных, полученных на предшествующем этапе развития науки, является методологической основой междисциплинарности.

Нельзя не согласиться с мнением Александра Швейцера, который, определяя состояние науки о переводе в конце XX века, писал:

Множественность моделей перевода отражает неединичность подходов к этому явлению, его междисциплинарный статус. Думается, что подлинно реалистическая картина этого сложного и многоаспектного процесса может быть получена лишь на основе интеграции различных, дополняющих друг друга подходов к его исследованию ${ }^{16}$.

Изучение перевода как объекта разных когнитивных наук позволило накопить немало весьма полезных научных данных об этом феномене, которые, видимо, могут быть интегрированы в единое научное знание.

Что же касается теории перевода, науки о переводе в целом, то она представляет собой концептуальную систему, некий идеальный конструкт, отражающий с большей или меньшей степенью приближения реальную систему. Разумеется, нет непреодолимой пропасти между переводом как реальной системой и наукой о переводе как системой концептуальной. Перевод как системная человеческая деятельность не может не реагировать на «внешние раздражители», в частности, такие, как смена носителей, фиксирующих информацию - от глиняных табличек до компьютера - в корне меняющих технологию переводческой деятельности и знаменующих реальные переходы к очередной новой стадии в истории перевода ${ }^{17}$.

${ }^{16}$ А.Д. Швейцер, Междисциплинарный статус теории перевода, «Тетради переводчика» 1999, № 24, с. 30.

${ }^{17}$ О.И. Костикова История перевода: предмет, методология, место в науке о переводе, «Вестник Московского университета. Серия 22. Теория перевода» 2011, № 2, c. 3-22. 
Теория перевода как концептуальная система фиксирует, изучает и описывает эти изменения настолько точно и подробно, насколько ей позволяет ее уровень научного развития: от обрывочных эмпирических «зарисовок» через построение «моделей» к синтетическому представлению о переводе как о некой управляемой системе.

Системное представление науки о переводе как об организованном научном знании позволяет воспользоваться многими идеями, выработанными общей теорией систем, в частности, идеей «черного ящика», обратной связи и реакции (feed-back).

Попытки такой интеграции, на наш взгляд, знаменуют зарождение, пока весьма робкое, новой научной парадигмы в науке о переводе, которая может быть определена как системологическая.

Синтез различных предметов с целью построения единой теории объекта, способный привести к созданию новой научной дисциплины, требует системного подхода. Иначе говоря, наука о переводе должна синтезировать различные предметные стороны переводческой деятельности как некой системы.

Системологическая парадигма науки о переводе ${ }^{18}$ строится на основе синтеза множества данных, воспринимаемых как нечто целое. Разумеется, синтезу как методу познания предшествует, а часто и сопутствует его антипод - анализ, который, разлагая целое на составляющие, постоянно подпитывает системологию новыми данными об изучаемом объекте.

Методологическая ценность системного подхода к переводу состоит в том, что он позволяет ориентировать исследование изучаемого объекта на раскрытие его целостности и на анализ тех механизмов, которые эту целостность обеспечивают. При этом особое внимание уделяется выявлению многообразных типов связей как внутри самого сложного объекта, так и с окружающим миром, что позволяет, в конечном итоге, свести разносторонние знания об объекте в единую теоретическую картину.

Системный подход, занимающий в современном научном познании одно из центральных мест, позволяет охватить более широкую познавательную реальность по сравнению с теми под-

${ }^{18}$ Н. К. Гарбовский, Системологическая модель науки о переводе. Трансдисциплинарность и система научных знаний, «Вестник Московского университета. Серия 22. Теория перевода» 2015, № 1, с. 3-20. 
ходами, когда исследования сосредоточивались лишь на какойлибо одной предметной стороне объекта. Системный подход к переводу способен дать более полную и подробную теоретическую картину этого объекта по сравнению с отдельно взятым лингвистическим, литературоведческим или каким-либо еще подходом.

В русле системного подхода не только предлагается новая схема объяснения механизмов, обеспечивающих целостность переводческой деятельности, но и разрабатываются такие типологии связей и отношений, которые представляют их как логически однородные. Это позволяет непосредственно сравнивать и сопоставлять между собой все многообразные типы связей и отношений, выявляемых в переводческой деятельности, на единых основаниях.

Наука о переводе пойдет новым галсом.

\section{REFERENCES}

Balliu, Christian. Clefs pour une histoire de la traductologie soviétique, "Meta" 2005, vol.50, no. 3: 934-948.

Ben'yamin,Val'ter. "Zadacha perevodchika. Predisloviye k perevodu Parizhskikh kartin Bodlera". Transl. Pavlova, Elena. Kommentarii 1997, no. 11, http://www. commentmag.ru/archive/11/ 6.htm (15.10.2020) [Беньямин, Вальтер. "Задача переводчика. Предисловие к переводу Парижских картин Бодлера". Перев. Павлова, Елена). Комментарии 1997, no. 11, http://www.commentmag.ru/archive/11/ 6.htm (15.10.2020)].

Chukovskiy, Korney. Vysokoye iskusstvo; Moskva: Sovetskiy pisatel', 1968 [Чyковский, Корней. Высокое искусство. Москва: Советский писатель, 1968].

Fedorov, Andrey. O khudozhestvennom perevode. Leningrad: OGIZ, 1941 [Федоров, Андрей. О художественном переводе. Ленинград: ОГИЗ, 1941].

Fedorov, Andrey. Osnovy obshchey teorii perevoda (lingvisticheskiye problemy), Moskva: Vysshaya shkola, 1983 [Федоров, Андрей. Основы общей теории перевода (лингвистические проблемы). Москва: Высшая школа, 1983].

Fedorov, Andrey. Vvedeniye $v$ teoriyu perevoda. Moskva: Izdatel'stvo literatury na inostrannykh yazykakh, 1953 [Федоров, Андрей. Введение в теорию перевода, Москва: Издательство литературы на иностранных языках, 1953].

Gal', Nora. Vospominaniya. Stati. Stikhi. Pis'ma. Bibliografiya, Kuz'min, Dmitry (sost.). Moskva: Argo-Risk, 1997 http://www.vavilon.ru/noragal/memoir. html (115.10.2020) [Галь, Нора. Воспоминания. Статьи. Стихи. Письма. Библиография, Кузьмин, Дмитрий (сост.). Москва: Арго-Риск, 1997, http:// www.vavilon.ru/noragal/memoir.html (15.10.2020)].

Garbovskiy, Nikolay. "Sistemologicheskaya model' nauki o perevode. Transdistsiplinarnost' i sistema nauchnykh znaniy.” Vestnik Moskovskogo universiteta. Seriya 22. Teoriya perevoda 2015, no. 1: 3-20 [Гарбовский, Николай. 
"Системологическая модель науки о переводе. Трансдисциплинарность и система научных знаний.” Вестник Московского университета. Серия 22. Теория перевода 2015, nо. 1: 3-20].

Gumilev, Nikolay. Perevody stikhotvornyye // Chukovskiy, Korney. Gumilev, Nikolai. Printsipy khudozhestvennogo perevoda, Peterburg: Vsemirnaya literatura, 1919: 25-30 [Гумилев, Николай. Переводы стихотворные. Чуковский, Корней. Гумилев, Николай. Принцииы художественного перевода, Петербург: Всемирная литература, 1919: 25-30].

Kashkin, Ivan. "Lozhnyy printsip i nepriyemlemyye rezul'taty." Inostrannyye yazyki v shkole 1952, no. 2. 22-41 [Кашкин, Иван. "Ложный принцип и неприемлемые результаты." Иностранные языки в школе 1952, по. 2. 22-41].

Komissarov, Vilen. Sovremennoye perevodovedeniye. Moskva: ETC, 2001 [Комиссаров, Вилен. Современное переводоведение. Москва: ЭТС, 2001].

Kostikova,Ol'ga. "Istoriya perevoda: predmet,metodologiya, mesto v nauke o perevode." Vestnik Moskovskogo universiteta. Seriya 22. Teoriya perevoda 2011, no. 2. 3-22 [Костикова, Ольга. "История перевода: предмет, методология, место в науке о переводе.” Вестник Московского университета. Серия 22. Теория перевода 2011, по. 2. 3-22].

Lann, Yevgeniy. "Stil' rannego Dikkensa i perevod Posmertnykh zapisok Pikvikskogo kluba." Literaturnyy kritik 1939, no. 1. 156-171 [Ланн, Евгений. "Стиль раннего Диккенса и перевод Посмертных записок Пиквикского клуба.” Литературный критик 1939, nо. 1.156-171].

Retsker, Yakov. Teoriya perevoda i perevodcheskaya praktika. Ocherki lingvisticheskoy teorii perevoda. Moskva: R. Valent, 2007 [Рецкер, Яков. Теория перевода и переводческая практика. Очерки лингвистической теории перевода. Москва: Р. Валент, 2007].

Shveytser, Aleksandr. "Mezhdistsiplinarnyy status teorii perevoda." Tetradi perevodchika 1999, nо. 24 [Швейцер, Александр. "Междисциплинарный статус теории перевода." Тетради переводчика 1999, no. 24].

Van Hoof, Henri. "La traduction au pays des Tsars et des Soviets." Meta 1990, vol. 35 , no. 2. 277-302. 